\title{
ENSINO MÉDIO INTEGRADO DO INSTITUTO FEDERAL E O ENSINO MÉDIO INTEGRAL E INTEGRADO DE MINAS GERAIS
}

\author{
Gisele Oliveira Ribeiro Wanzeler; Admilson Eustáquio Prates \\ Instituto Federal de Educação, Ciência e Tecnologia do Norte de Minas Gerais \\ DOI: $10.15628 /$ rbept.2019.8568
}

Artigo submetido em abr/2019 e aceito em maio/2019

\begin{abstract}
RESUMO
Este estudo tem como objetivo analisar o Ensino Médio Integrado do Instituto Federal de Minas Gerais - campus Ribeirão das Neves e o Ensino Médio Integral Integrado de Minas Gerais. Para alcançarmos o objetivo traçado neste estudo, realizamos revisão bibliográfica acerca do tema e análise documental, utilizando, para o tratamento dos dados, a análise por categorias proposta por Bardin (2002). Os documentos analisados foram: o Documento Orientador do Projeto Pedagógico para escolas Pólo de Educação Múltipla/ POLEM, que ofertam Ensino Médio Integral e Integrado/2018 da Secretaria de Estado de Educação de Minas Gerais; e o Projeto Pedagógico do Curso Técnico em Administração Integrado ao Ensino Médio /2017 do Instituto Federal de Minas Gerais/Ribeirão das Neves. As categorias analisadas foram: Finalidade e Concepção do Ensino Médio Integral/Integrado; as formas de oferta do curso e ingresso; carga horária e currículo integrado. Através deste estudo, pode-se concluir que o Ensino Médio Integrado do IFMG de Ribeirão das Neves propõe a integração da formação geral e formação profissional. O Ensino Médio Integral e Integrado de Minas Gerais propõe a integração dos componentes da Base Nacional Comum (formação básica) com a parte Flexível do Currículo, com a possibilidade de um curso técnico profissionalizante. As duas propostas têm aspectos distintos, mas enfatizam uma formação humana integral e a adoção de um currículo integrado.
\end{abstract}

Palavras-Chave: Ensino médio integrado. Ensino Médio Integral e Integrado. Currículo integrado. Educação profissional.

\section{INTEGRATED MIDDLE SCHOOL OF THE FEDERAL INSTITUTE AND INTEGRATED AVERAGE AND INTEGRATED MINAS GERAIS}

\begin{abstract}
This study aims to analyze the Integrated High School of the Federal Institute of Minas Gerais Ribeirão das Neves campus and the Integral Integrated High School of Minas Gerais. In order to reach the objective outlined in this study, we performed bibliographic review on the subject and documentary analysis, using for the treatment of data, the analysis by categories proposed by Bardin (2002). The documents analyzed were: the Guidance Document of the Pedagogical Project for Schools of Multiple Education / POLEM that offer Integral and Integrated Secondary Education / 2018 of the State Secretariat of Education of Minas Gerais and the Pedagogical Project of the Technical Course in Integrated Administration to Secondary Education / 2017 of the Federal Institute of Minas Gerais / Ribeirão das Neves and the categories analyzed were: Purpose and Conception of Integral / Integrated High School; the forms of course offer and admission; workload and integrated curriculum. Through this study it can be concluded that the Integrated High School of the IFMG of Ribeirão das Neves proposes the integration of general education and vocational training and the Integral and Integrated High School of Minas Gerais proposes the integration of the components of the Common National Base (basic training) with the Flexible part of the Curriculum and with the possibility of a professional technical course. The two proposals have distinct aspects, but they emphasize integral human formation and the adoption of an integrated curriculum.
\end{abstract}

Keywords: Integrated secondary education. Integral and Integrated High School. integrated curriculum. Professional education. 


\section{INTRODUÇÃO}

O sistema educacional brasileiro compõe-se da educação básica constituída pela educação infantil, ensino fundamental e ensino médio - e da educação superior. $O$ ensino médio é a última etapa da educação básica e tem a duração mínima de 3 (três) anos, conforme Lei de Diretrizes e Bases da Educação (LDB, Lei no 9.394/1996).

O Brasil sempre foi marcado pela dualidade em seu sistema educacional atendendo às necessidades da divisão entre capital de trabalho e o ensino médio, etapa final da educação básica, foi a maior expressão desta situação através de uma formação geral e profissional (RAMOS, 2010).

Em 1996, com a aprovação da LDB o 9.394/1996, a educação profissional permaneceu como uma modalidade separada da educação básica. Esta situação foi reforçada com a publicação do Decreto ํo 2.208 de 17 de Abril de 1997, em que a separação entre o ensino médio e a educação profissional foi novamente reafirmada, retomando-se à histórica dicotomia: educação profissional ${ }^{1}$ versus educação geral ${ }^{2}$.

Em 23 de Julho de 2004, o Decreto o 5.154 foi publicado revogando o Decreto $n^{\circ} 2.208 / 97$. Ele regulamentou o $\S 2^{\circ}$ do artigo 36 e os artigos 39 a 41 da Lei no 9.394/1996, mantendo a educação profissional como etapa formativa própria, mas, agora, articulada ao ensino médio. Com a publicação da Lei no 11.741 de 16 de julho de 2018, a educação profissional técnica de nível médio passou a ser uma modalidade do ensino médio.

Hoje, a Lei de Diretrizes e Bases da Educação Nacional (LDB, Lei oo 9.394/1996) apresenta que o ensino médio pode preparar o educando para exercer uma profissão, desde que a formação geral ${ }^{3}$ seja atendida. A LDB no 9.394/1996 apresenta, ainda, que esta educação técnica de nível médio pode ocorrer da seguinte maneira: articulada ao ensino médio de forma integrada com matrícula única na mesma instituição em que o aluno está cursando o ensino médio; articulada ao ensino médio de forma concomitante para aqueles que estão iniciando ou já cursando o ensino médio com matrículas distintas para cada curso, podendo ser na mesma instituição em que o estudante já cursa o ensino médio ou em outra instituição; e, também, na forma subsequente em que o estudante, após concluir o ensino médio, faz apenas o curso técnico.

O Caderno 1 (um) de Formação de Professores, da etapa I do Pacto Nacional pelo Fortalecimento do Ensino Médio $^{4}$, aborda que o ensino médio no

\footnotetext{
${ }^{1} \mathrm{~A}$ educação profissional era destina à classe trabalhadora através de uma formação técnica exigida pelo mercado de trabalho (BRASIL, 2007).

${ }^{2}$ A educação geral se dava através de um ensino propedêutico, proporcionando aos filhos da classe dirigente uma formação que possibilitasse à continuidade dos estudos em nível superior (BRASIL, 2007).

${ }^{3} \mathrm{~A}$ formação geral se refere aos componentes curriculares das quatro áreas do conhecimento: linguagens e suas tecnologias; matemática e suas tecnologias; ciências da natureza e suas tecnologias; ciências humanas e sociais aplicadas e suas tecnologias (BRASIL, 1996).

${ }^{4}$ O Pacto Nacional pelo Fortalecimento do Ensino Médio foi instituído pela Portaria no 1.140 , de 22 de novembro de 2013 em que o Ministério da Educação - MEC e as secretarias estaduais e distritais da educação, de forma articulada, assumiram o compromisso com a valorização da 
Brasil é configurado, atualmente, de quatros formas: Regular, Normal/Magistério, Integrado à Educação Profissional (Integrado) e o Ensino Médio da Educação de Jovens e Adultos (EJA). O caderno ainda apresenta os grupos de estudantes que compõem o ensino médio, sendo que um deles se refere a um grupo muito pequeno de estudantes da rede federal no ensino médio integrado; e outro grupo, também pequeno, correspondente aos estudantes do ensino médio integrado da rede estadual (BRASIL, 2013).

O ensino médio integrado da rede federal é ofertado pelos Institutos Federais de Educação, Ciência e Tecnologia ${ }^{5}$, sendo que uma de suas finalidades é garantir o mínimo $50 \%$ (cinquenta por cento) de suas vagas para a oferta do ensino médio integrado. $O$ site $^{6}$ da Rede Federal de Educação Profissional Científica e Tecnológica apresenta que, atualmente, o Brasil conta com 38 Institutos Federais e 644 campi em funcionamento, presentes em todos os estados. O Ensino Médio Integrado na rede federal propõe a unidade entre a formação geral e a formação profissional.

A respeito do ensino médio integrado da rede estadual, podemos abordar o estado de Minas Gerais, que com a adesão ao Programa de Fomento à Implementação de Escolas em Tempo Integral ${ }^{7}$, teve 44 escolas selecionadas para implementarem o ensino médio integral. Em junho de 2017, com a Portaria no 727/2017, estabeleceram-se novas diretrizes, parâmetros e critérios para o Programa de Fomento às Escolas de Ensino Médio em Tempo Integral, assim, o estado de Minas Gerais ampliou sua oferta de ensino médio integral para mais 35

formação continuada dos professores e coordenadores pedagógicos que atuavam no ensino médio. A formação ofertada pelo Programa foi desenvolvida na modalidade presencial. $\mathrm{Na}$ primeira etapa, o processo formativo se deu através do estudo de seis Cadernos de Formação do Professor, sendo eles: Ensino médio e formação humana integral; O jovem como sujeito do ensino médio; Currículo do ensino médio, seus sujeitos e o desafio da formação humana integral; Áreas de conhecimento e integração curricular; Organização e gestão democrática da escola; Avaliação no ensino médio. Na segunda etapa, foram estudados os Cadernos de Formação do Professor referente à Organização do trabalho pedagógico no ensino médio e para as áreas do conhecimento: Ciências Humanas, Ciências da Natureza, Linguagens e Matemática.

${ }^{5}$ Com a publicação da Lei Federal no $11.892 / 2008$, foi instituída a Rede Federal de Educação Profissional, vinculada ao Ministério da Educação e constituída por: Institutos Federais de Educação, Ciência e Tecnologia - Institutos Federais; Universidade Tecnológica Federal do Paraná - UTFPR; Centros Federais de Educação Tecnológica Celso Suckow da Fonseca CEFET-RJ - e de Minas Gerais - CEFET-MG; e acrescentadas em 2012, pela Lei Federal no 12.677, as escolas técnicas vinculadas às universidades federais e o Colégio Pedro II. Os Institutos Federais, conforme 0 artigo $2^{0}$ da Lei $n^{0}$ 11.892/2008, são denominadas como "instituições de educação superior, básica e profissional, pluricurriculares e multicampi, especializados na oferta de educação profissional e tecnológica nas diferentes modalidades de ensino" (BRASIL, 2008).

${ }_{7}^{6} \mathrm{http}: / /$ redefederal.mec.gov.br/expansao-da-rede-federal

7 A Medida Provisória $\mathrm{n}^{\circ}$ 746, de 22 de setembro de 2016, convertida posteriormente na Lei $\mathrm{n}^{\circ}$ 13.415, de 16 de fevereiro de 2017, instituiu, no âmbito do Ministério da Educação, a Política de Fomento à Implementação de Escolas de Ensino Médio em Tempo Integral. Esta Política de Fomento prevê que o Ministério da Educação repassasse recursos às Secretarias Estaduais e Distrital de Educação - SEE que implantarem o ensino médio integral em suas escolas. Este repasse financeiro corresponde ao valor anual de $R \$ 2.000,00$ (dois mil reais) por aluno, e foi ampliado de 4 (quatro) para 10 anos com a promulgação da Lei 13.415/2017. Em 10 de outubro de 2016 o Ministério da Educação - MEC, criou a Portaria no 1.145/2016 que institui o Programa de Fomento à Implementação de Escolas em Tempo Integral. Este programa visa apoiar a implementação da proposta pedagógica de escolas de ensino médio em tempo integral das redes públicas dos estados e do Distrito Federal e fez parte da reforma do Ensino Médio. 
escolas. Hoje, 79 escolas implantaram o ensino médio integral, correspondendo a 66 municípios. Este projeto de ensino médio, em Minas Gerais, é denominado de Ensino Médio Integral e Integrado. Propõe a integração dos componentes da Base Nacional Comum (formação básica) à parte Flexível $^{8}$ do Currículo com a possibilidade de um curso técnico profissionalizante.

Até o este momento, vimos que, tanto a rede federal quanto a rede estadual ofertam o ensino médio integrado. Percebemos, deste modo, que há diferenças nas nomenclaturas dos projetos de ensino médio das duas redes. Indagamo-nos, para tanto, sobre quais os pontos comuns e/ou divergentes dos projetos de ensino médio da rede federal e rede estadual de Minas Gerais. Deste modo, este estudo tem como objetivo analisar o Ensino Médio Integrado do Instituto Federal de Minas Gerais - campus Ribeirão das Neves e o Ensino Médio Integral Integrado de Minas Gerais.

Para alcançarmos o objetivo traçado neste estudo, realizamos revisão bibliográfica acerca do tema e análise documental. A análise documental baseouse em Bardin (2002), definida como "um conjunto de técnicas de análise das comunicações que utiliza procedimentos sistemáticos e objetivos de descrição do conteúdo das mensagens" (BARDIN, 2002, p. 38). Este autor estabelece três fases da análise de conteúdo: pré-análise; exploração do material e o tratamento dos resultados; a inferência e a interpretação. Utilizamos, para tratamento dos dados, a análise por categorias proposta por Bardin (2002). Os documentos analisados foram: o Documento Orientador do Projeto Pedagógico para escolas Polo de Educação Múltipla/ POLEM, que ofertam Ensino Médio Integral e Integrado/2018, da Secretaria de Estado de Educação de Minas Gerais; e o Projeto Pedagógico do Curso Técnico em Administração Integrado ao Ensino Médio/2017, do Instituto Federal de Minas Gerais/Campus Ribeirão das Neves.

O Projeto Pedagógico do Curso Técnico em Administração Integrado ao Ensino Médio/2017 é constituído pelos seguintes tópicos: Contextualização da instituição; Concepção do curso; Estrutura do curso; Procedimentos de avaliação; Considerações finais; Referências e Apêndices. O Documento Orientador do Projeto Pedagógico para escolas Polo de Educação Múltipla/POLEM que ofertam Ensino Médio Integral e Integrado/2018 do EMII/SEEMG apresenta os seguintes tópicos: Educação Integral e Integrada no Estado de Minas Gerais; O perfil do jovem e os desafios do ensino médio; Diretrizes para a implantação da Educação em Tempo Integral nas escolas de ensino médio de Minas Gerais (organização pedagógica; passo a passo da implantação do programa; financiamento do programa; avaliação; participação da comunidade), Considerações finais, Referências bibliográficas e Anexos. Escolhemos quatro categorias para análise destes documentos: finalidade e concepção; oferta do curso; carga horária e currículo integrado. Para embasamento teórico utilizamos os autores Ramos e Ciavatta (2012), Ramos (2010), Ciavatta (2010), Araújo e Frigotto (2015) e o estudo de legislações.

\footnotetext{
${ }^{8}$ No currículo flexível, os estudantes, a partir de um leque de opções, escolhem o percurso mais adequado aos seus objetivos e projeto de vida. A parte flexível do currículo do EMII/SEEMG é composta pelos Campos de Integração Curricular e/ou pelo Curso Técnico profissionalizante. Assim, os estudantes (em maioria) podem escolher as disciplinas que desejam cursar referente aos 3 (três) Campos de Integração Curricular e também podem escolher um Curso Técnico profissionalizante dentre os 11 (onze) que são oferecidos pela Rede de Educação Profissional Tecnológica de Minas Gerais.
} 


\section{CONTEXTUALIZANDO A PESQUISA}

Segundo a Lei Federal oㅜ 11.892/2008, os Institutos Federais possuem autonomia para criar cursos e autonomia didático-pedagógica ${ }^{9}$, ou seja, possuem autonomia para planejar, implantar, desenvolver os cursos de ensino médio integrado. A fim de estabelecer uma comparação entre o ensino médio integrado da rede estadual de Minas Gerais e o da rede federal, escolhemos um Instituto Federal em Minas Gerais que ofertasse o mesmo curso técnico integrado ofertado pela rede estadual, neste caso, o curso escolhido foi o técnico em administração.

$\mathrm{Na}$ escolha do Instituto Federal a ser pesquisado, verificamos que em Minas Gerais há cinco Institutos Federais ${ }^{10}$. Realizando uma pesquisa no portal dos Institutos Federais do estado de MG sobre a oferta do ensino médio integrado ao técnico em administração, foi possível chegar aos seguintes resultados: o IFNMG não oferta o técnico em administração integrado ao ensino médio, este curso é ofertado somente na forma subsequente no campus Almenara e concomitante nos campi Arinos, Janaúba, Pirapora e Teófilo Otoni. No IF Sudeste de Minas o técnico em Administração é ofertado na forma subsequente nos campi Rio Pomba e São João Del Rei.

No IF Triângulo Mineiro o técnico em administração é ofertado integrado ao ensino médio nos campi Patrocínio e Uberlândia, na forma integrada e concomitante nos campi Paracatu e Uberaba e concomitante nos campi Campina Verde, Ituiutaba. No IF Sul de Minas o técnico em Administração integrado ao médio é ofertado nos campi Pouso Alegre e Três Corações e na forma subsequente nos campi Machado, Muzambinho, Poços de Caldas, Pouso Alegre, Carmo de Minas, Três Corações e Itanhandu. O IFMG é o Instituto que possui a maior quantidade de campi ofertando o técnico em administração integrado ao médio, sendo estes: Bambuí, Formiga, Ouro Branco, Ouro Preto, Ponte Nova, Ribeirão das Neves, Sabará; ofertando, ainda na forma subsequente, nos campi Ponte Nova e Ribeirão das Neves.

Dentre tantos campi que ofertam o ensino médio integrado ao técnico em administração escolhemos o Campus Ribeirão das Neves/IFMG, por ser o Instituto que disponibilizou em seu site o Projeto Pedagógico do Curso Técnico em Administração Integrado ao Ensino Médio mais recente.

O Ensino Médio Integral e Integrado da rede estadual de Minas Gerais possui duas modalidades: uma integrada ao Curso Técnico Profissionalizante e

\footnotetext{
9 "A autonomia administrativa, patrimonial, financeira, didático-pedagógica e disciplinar destas instituições é uma autonomia relativa e limitada por aquilo e somente aquilo que a lei prevê como possível de ser definido pela instituição"(CRUZ SOBRINHO, 2018, p.37).

${ }^{10}$ Instituto Federal de Educação, Ciência e Tecnologia do Sul de Minas Gerais- IFSULMINAS; Instituto Federal de Educação, Ciência e Tecnologiade Minas Gerais - IFMG; Instituto Federal de Educação, Ciência e Tecnologia do Sudeste de Minas Gerais - IFSUDESTEMG; Instituto Federal de Educação, Ciência e Tecnologia do Triângulo Mineiro - IFTM e o Instituto Federal de Educação, Ciência e Tecnologia do Norte de Minas Gerais -IFNMG.
} 
outra integrada aos Campos de Integração Curricular ${ }^{11}$. Escolhemos somente a modalidade integrada ao Curso Técnico em Administração para análise.

A partir daqui traçaremos a análise destes dois projetos de ensino médio e adotaremos a sigla EMI/IFMG para o Ensino Médio Integrado do Instituto Federal de Minas Gerais/Campus Ribeirão das Neves, e a sigla EMII/SEEMG para o Ensino Médio Integral e Integrado da Rede Estadual de Minas Gerais.

\section{FINALIDADE E CONCEPÇÃO DO ENSINO MÉDIO INTEGRAL/INTEGRADO}

O EMI/IFMG apresenta uma modalidade que é a integrada ao Curso Técnico e o seu conceito do termo "integrado" se refere à integração do Curso Técnico à Formação Geral. O EMI/IFMG se compromete a proporcionar uma formação humana integral articulando à educação profissional e tecnológica ao trabalho, ciência, tecnologia e cultura, com o objetivo de "formar profissionaiscidadãos técnicos de nível médio, competentes técnica, ética e politicamente e com elevado grau de responsabilidade social" (IFMG, 2017, p.30).

O EMII/SEEMG apresenta duas modalidades em sua proposta: uma integrada ao Curso Técnico e outra integrada aos Campos de Integração Curricular. O entendimento do termo "integral e integrado" do EMII/SEEMG não está explícito no Documento Orientador da proposta pedagógica, assim recorremos ao Documento Orientador da Política de Educação Integral e Integrada e Implementação das Escolas Polo de Educação Múltipla em Minas Gerais, que aborda o termo integral como referente à formação humana integral e o termo integrado referido à integração das dimensões cognitiva, afetiva, ética, estética, cultural, social e política, sendo o curso técnico e os campos de integração curricular possibilidades para esta integração (MINAS GERAIS, 2017).

O Documento Orientador do EMII/SEEMG não deixa explícito sobre os objetivos do curso integrado ao técnico em administração. Recorremos, então, à Portaria ำ 727/2017, no parágrafo único do artigo 1ํㅡㄹ em que aborda que a proposta pedagógica das escolas de ensino médio em tempo integral terá por base a ampliação da jornada escolar e a formação integral e integrada do estudante. O EMII/SEEMG apresenta que a finalidade dessa ampliação da jornada

\footnotetext{
${ }^{11} \mathrm{O}$ campo de Integração Curricular é "uma ação curricular ou em um conjunto de atividades pedagógicas e coletivas, realizadas com grupos de estudantes em que se desenvolvem de forma integrada os conhecimentos e saberes, relacionando-os com os conceitos e conteúdos trabalhados nos componentes curriculares da base comum, explorando os tempos e o mais variados espaços da escola e do território, e construindo com os sujeitos envolvidos as ações de aprendizagem" (MINAS GERAIS, 2019, p. 42). O Ensino Médio Integral e Integrado prevê três Campos de Integração Curricular: Cultura, Arte e Cidadania; Múltiplas Linguagens, Comunicação e Mídias; Pesquisa e Inovação Tecnológica. Nestes campos são previstas aulas de Música, Artes Plásticas, Artes Marciais, Dança, Esportes, Animação Digital, Cinema, Designer Gráfico, Fotografia, Grafite, Iniciação Científica, Introdução às Engenharias, Inovação Sustentável, Empreendedorismo, Robótica, Construção Sustentável, Desenvolvimento de Aplicativos e Softwares, entre tantas outras opções disponíveis no Documento Orientador da Proposta Pedagógica do EMII/SEMG. Para cada Campo de Integração Curricular são previstas uma quantidade específica de aulas, que são escolhidas pelos estudantes, pela maioria, no ato da matrícula. Estes Campos de Integração devem focar atividades que favoreçam conhecimentos além daqueles previstos nos componentes curriculares da Base Comum, mas ao mesmo tempo articulados a eles.
} 
escolar é oferecer aos estudantes uma Educação Integral através da integração da formação básica a diferentes conteúdos e vivências,

[...] garantindo-Ihes a melhoria das aprendizagens em todas as áreas do conhecimento, a construção e execução de um plano de participação cidadã, a promoção e o desenvolvimento de habilidades e de atuação social e, inclusive, a possibilidade de fazer um Curso Técnico profissionalizante. (MINAS GERAIS, 2018, p.9,10).

Segundo Ramos e Ciavatta (2012), o termo educação integral traz a ideia de uma educação mais completa, mas, por outro lado, se reduz à ampliação da jornada escolar e aos diferentes recursos pedagógicos. Se considerarmos o EMII/SEEMG somente como uma oferta de um ensino médio integral, poderíamos dizer que sua finalidade se reduziria à ampliação da jornada escolar, mas, como já visto antes, também se refere a um ensino médio integrado, articulando-se a outros conteúdos e experiências com a possibilidade de integração a um curso técnico profissionalizante.

Percebemos, assim, que a formação profissional é uma das possibilidades do EMII/SEEMG e não a sua finalidade principal. O Documento Orientador do EMII/SEEMG, ao tratar sobre currículo, apresenta sobre se garantir aos estudantes uma "formação integral, gerando reflexão crítica e autonomia" (MINAS GERAIS, 2018, p.10). Compreendemos, então, que a finalidade do EMII/SEEMG é oferecer aos estudantes uma formação humana integral através da integração da formação básica a outros conteúdos e experiências - sendo que uma das opções é o curso técnico profissionalizante - proporcionando, deste modo, aos estudantes, a melhoria das aprendizagens, a construção do seu projeto de vida e atuação no meio onde vivem.

Os autores Ramos (2008), Frigotto (2010), Ciavatta (2010), compreendem por ensino médio integrado a relação entre ensino médio e educação profissional, reafirmando a proposta de ensino médio do EMI/IFMG e podendo ser aplicado ao EMII/SEEMG. A formação integrada

[...] sugere tornar íntegro, inteiro, o ser humano dividido pela divisão social do trabalho entre a ação de executar e a ação de pensar, dirigir ou planejar. Trata-se de superar a redução da preparação para o trabalho ao seu aspecto operacional, simplificado, escoimado dos conhecimentos que estão na sua gênese científico tecnológica e na sua apropriação histórico-social (CIAVATTA, 2010, p.85).

O ensino médio integrado não se resume apenas ao agrupamento dos componentes curriculares da formação geral e da formação profissional. É mais do que isso, tratam-se das integrações das dimensões estruturantes da vida trabalho, ciência e cultura - possibilitando novas perspectivas aos estudantes e contribuindo na superação das desigualdades sociais (RAMOS, CIAVATTA, 2012).

Nesta mesma perspectiva, os autores Araújo e Frigotto (2015) também compreendem o ensino integrado não somente como modo de oferta da educação 
profissional de nível médio, mas como proposta pedagógica comprometida com o ideal de uma formação inteira capaz de "promover a autonomia e ampliar os horizontes (a liberdade) dos sujeitos das práticas pedagógicas, professores e alunos, principalmente" (ARAÚJO; FRIGOTTO, 2015, p.63).

\begin{abstract}
Portanto, o termo integrado remete, por um lado, à forma de oferta do ensino médio articulado com a educação profissional; mas, por outro, remete a um tipo de formação que seja integrada, plena, vindo a possibilitar ao educando a compreensão das partes no seu todo ou da unidade no diverso. Tratando-se a educação como uma totalidade social, são as múltiplas mediações históricas que concretizam os processos educativos (RAMOS; CIAVATTA, 2012, p. 308).
\end{abstract}

Verificamos que, as duas propostas de ensino médio têm como finalidade a formação humana integral dos estudantes. Segundo Ciavatta (2010), a formação humana busca "[...] garantir ao adolescente, ao jovem e ao adulto trabalhador o direito a uma formação completa para a leitura do mundo e para a atuação como cidadão pertencente a um país, integrado dignamente à sua sociedade política" (CIAVATTA, 2010, p.85). Assim, esta formação humana integral ora acontecerá articulando a formação básica a outros conteúdos e experiências - EMII/SEEMG, ora articulando a educação profissional e tecnológica ao trabalho, ciência, tecnologia e cultura - EMI/IFMG.

\title{
4 AS FORMAS DE OFERTA DO CURSO E INGRESSO
}

O EMI/IFMG é ofertado na modalidade presencial e em conformidade com Catálogo Nacional de Cursos Técnicos da Secretaria de Educação Profissional e Tecnológica do Ministério da Educação ${ }^{12}$. Para implantar o curso do ensino médio integrado ao técnico em administração foi realizado um diagnóstico da realidade da Região Metropolitana de Belo Horizonte, onde está localizado o campus Ribeirão das Neves, e verificaram-se argumentos para a sua implantação, dentre estes podemos destacar a necessidade de uma formação básica e de um curso técnico público e de qualidade; grande demanda por profissionais em Administração; a estrutura produtiva do local favorecer a atuação dos profissionais egressos deste curso.

O EMII/SEEMG também é ofertado na modalidade presencial. O curso técnico só pode ser ofertado se cumpridos 3 (três) requisitos: interesse dos alunos; após consulta e aprovação da comunidade; número de turmas do Ensino Médio Integral e Integrado à parte flexível dos Campos de Integração Curricular, por exemplo: se a escola tiver de duas até três turmas de $1^{\circ}$ ano, poderá ofertar apenas uma turma de Técnico Profissionalizante, se tiver de 4 a 6 turmas do $1^{\circ}$ ano, poderá ofertar duas turmas do Técnico Profissionalizante, e assim por diante. Cada escola tem a opção de ofertar o curso técnico dentre os 11 (onze) $\operatorname{cursos}^{13}$

\footnotetext{
${ }^{12}$ Disponível em: http://portal.mec.gov.br/escola-ativa/30000-uncategorised/52031-catalogonacional-de-cursos-tecnicos

13“Técnico em Administração; Técnico em Cooperativismo; Técnico em Informática; Técnico em Informática para a Internet; Técnico em Logística; Técnico em Marketing; Técnico em Recursos 
que também são oferecidos pela Rede de Educação Profissional Tecnológica de Minas Gerais. Confirmado o interesse dos estudantes do $1^{\circ}$ ano médio pela integração do Curso Técnico, a escola organiza um seminário de Mostra de Cursos Técnicos para os estudantes, com convite estendido às famílias ou responsáveis, para que a escolha do curso técnico não se dê de forma aleatória, e sim com base em informações sobre o que é o curso, as áreas de atuação de cada curso, expectativa de salário, estrutura produtiva da região. O curso técnico escolhido pela maioria dos estudantes é aquele ofertado no decorrer do ano letivo. O EMII/SEEMG obedece à Matriz Curricular e ao Plano de Curso, aprovados pelo Conselho Estadual de Educação.

As formas de ingresso nestes dois projetos de ensino médio são diferentes, apesar de a conclusão do ensino fundamental ser requisito nas duas propostas. No EMII/SEEMG, o Documento Orientador não deixa explícita a forma de ingresso neste curso, assim, por se tratar de um ensino público estadual, recorremos à Resolução SEE no 3765/2018, em que aborda que os alunos concluintes do ensino fundamental são encaminhados pela Comissão de Cadastro e Matrícula para as escolas que ofertam o ensino médio conforme os seguintes critérios: se a escola onde aluno concluiu o ensino fundamental também ofertar o ensino médio a sua vaga estará garantida, em caso contrário, ou quando a quantidade de vagas for insuficiente, leva-se em consideração a idade do estudante e a facilidade de acesso à escola de ensino médio que oferte EMII/SEEMG.

No EMI/IFNMG é necessário que o estudante tenha concluído o ensino fundamental e seja aprovado no processo seletivo do IFMG ou vir transferido em processos deferidos internos ou externos. Recorremos aos editais $n^{\circ}=91 / 2017^{14}$ e $92 /{ }^{15}$ do IFMG/Campus Ribeirão das Neves, que definem normas gerais para ingresso por meio de prova nos cursos técnicos integrados: prova objetiva com 50 (cinquenta) questões: 15 (quinze) questões de Língua Portuguesa e 15 (quinze) de Matemática; 10 (dez) questões de Ciências da Natureza e 10 (dez) de Ciências Humanas. A matriz de referência para elaboração da prova objetiva é baseada no Currículo Básico Comum do Ensino Fundamental do 6ำ ao 9ำ ano; $50 \%$ das vagas serão destinadas ao acesso pela modalidade de vagas reservadas - 8 grupos compostos por candidatos que tenham cursado integralmente 0 ensino fundamental em escolas públicas; $50 \%$ das vagas serão destinadas à modalidade de ampla concorrência.

O Documento base da Educação Profissional Técnica de Nível Médio Integrada ao Ensino Médio apresenta que uma das possibilidades de os filhos da classe trabalhadora terem uma educação de qualidade, uma formação integral que contribua para a sua inserção no mundo do trabalho, é o ingresso nos Institutos Federais, entretanto "tornar-se aluno dessas escolas não é fácil, pois a concorrência nos processos seletivos é muito elevada, uma vez que a quantidade de vagas que podem oferecer é muito menor do que a demanda" (BRASIL, 2007, p.26).

Humanos; Técnico em Secretariado; Técnico em Secretariado Escolar; Técnico em Serviços Públicos; Técnico em Transações Imobiliárias" (MINAS GERAIS, 2018, p.23).

${ }^{14}$ Disponível em: https://www.ifmg.edu.br/portal/noticias/edital91.pdf

${ }^{15}$ Disponível em: https://www.ifmg.edu.br/portal/noticias/edital-com-regras-gerais-sobre-o-ingressono-ifmg-e-divulgado/edital-92-complementar-cursos-tecnicos.pdf 
As autoras Artiaga e Alves (2017), em uma pesquisa realizada com os egressos do ensino médio integrado do Instituto Federal Sudeste de Minas Gerais, avançam nesta discussão quando apresentam ainda outra questão referente ao processo seletivo dos Institutos Federais: o público-alvo do ensino médio integrado dos Institutos Federais, que são os filhos da classe trabalhadora, muitas vezes não é beneficiado, pois não consegue ocupar uma vaga por meio do processo seletivo. As autoras ainda abordam que, predominantemente, os estudantes que ingressam no ensino médio integrado têm como objetivo 0 ingresso no curso superior e não a finalidade de seguir a carreira como técnicos na sua área de formação.

Verificamos que, apesar de o EMII/SEEMG não exigir aprovação em processo seletivo, não garante a todo estudante concluinte do ensino fundamental a sua matrícula em uma escola de ensino médio integral e integrado e nem a formação técnica profissionalizante, uma vez que a oferta do curso técnico depende dos vários fatores já citados, e que no estado de Minas Gerais somente 79 escolas participam deste programa, não obtendo, portanto, vagas suficientes para atender à demanda, assim como ocorre nos Institutos Federais.

A diferença na forma de ingresso no ensino médio das instituições federais e estaduais também é demonstrada nos resultados das avaliações externas $^{16}$. Segundo Silva e Ramos (2018), um dos motivos dos estudantes da rede federal obter bom desempenho se dá pelo fato de já terem obtido uma boa performance no concorrido processo de seleção, observada pela aprovação no mesmo.

\section{A CARGA HORÁRIA DO ENSINO MÉDIO INTEGRAL/INTEGRADO}

As duas propostas de ensino médio têm a duração de 3 (três) anos. A modalidade integrada ao curso técnico possui matrícula única em ambas, mas a carga horária é diferente. A carga horária do EMI/IFMG corresponde a um total de 3.100 horas, sendo que 2.130 horas correspondem aos componentes curriculares das áreas de linguagens, códigos e suas tecnologias, ciências humanas e suas tecnologias; e ciências da natureza, matemática e suas tecnologias; 900 horas correspondem à formação técnica profissionalizante e 70 horas se referem ao núcleo de prática profissional. Já o EMII/SEEMG possui uma carga horária superior, num total de 4.500 horas, sendo 3.000 horas destinadas à Base Nacional Comum (possui três aulas a mais de português e matemática e uma aula a mais de Língua estrangeira); 1.000 horas destinadas à formação técnica e 500 horas aos Campos de Integração Curricular, sendo assim, possui 1400 horas a mais. A carga horária maior dos componentes de Língua Portuguesa e Matemática e do currículo flexível do EMII/SEEMG obedece às normativas da Portaria nํㅜ 727/2017,

\footnotetext{
${ }^{16}$ Também chamada de avaliação em larga escala, a avaliação externa é um dos principais instrumentos para a elaboração de políticas públicas dos sistemas de ensino e redirecionamento das metas das unidades escolares. Seu foco é o desempenho da escola e o seu resultado é uma medida de proficiência que possibilita aos gestores a implementação de políticas públicas e às unidades escolares um retrato de seu desempenho (CAED). Disponível em: http://www.portalavaliacao.caedufjf.net/pagina-exemplo/tipos-de-avaliacao/avaliacao-externa/
} 
em que prevê pelo menos 300 (trezentos) minutos semanais dedicados à Língua Portuguesa e Matemática e 500 (quinhentos) minutos semanais dedicados a atividades da parte flexível ${ }^{17}$.

Devemos considerar que, conforme a LDB no 9.394/1996, a carga horária mínima para o ensino médio regular é de 800 horas anuais devendo ser ampliada progressivamente para 1400 horas, como prazo máximo de 5 anos (a partir de 02 de março de 2017) para os sistemas de ensino oferecer pelo menos 1000 horas. Percebemos, dessa maneira, que os EMI/IFMG e o EMII/SEEMG já cumprem esta determinação e oferecem aos seus estudantes uma jornada escolar ampliada. Percebemos, ainda, que estes dois projetos de ensino médio vão ao encontro da Meta 10 do Plano Nacional de Educação, que propõe oferecer, no mínimo, 25\% (vinte e cinco por cento) das matrículas na forma integrada à educação profissional para os jovens e adultos do ensino fundamental e médio.

Cabe aqui, ainda, refletirmos sobre quais as condições e os objetivos para se ampliar a jornada escolar, uma vez que a ampliação da jornada não significa necessariamente em formação integral: "sem a perspectiva de formação humana integral, claramente explicitada na flexibilização curricular, a mera ampliação do tempo não configurará a perspectiva de escolas de tempo e formação humana integral" (MOLL, 2017, p.69).

\section{O CURRÍ́CULO}

A proposta curricular do EMI/IFMG prevê integração entre formação geral e formação profissional. Sua proposta pedagógica gira em torno de núcleos politécnicos proporcionando condições de uma prática interdisciplinar. O Projeto Pedagógico do Curso não deixa explícito o conceito de núcleos politécnicos, mas entendemos que se referem ao agrupamento das disciplinas por áreas comuns. Os núcleos politécnicos são organizados em:

-Núcleo Estruturante (NE): relativo a conhecimentos do ensino médio (linguagens, códigos e suas tecnologias; ciências humanas e suas tecnologias; e ciências da natureza, matemática e suas tecnologias), contemplando conteúdos de base científica e cultural basilares para a formação humana integral;

- Núcleo Articulador (NA): relativo a conhecimentos do ensino médio e da educação profissional, que destacam mais propriamente o caráter interdisciplinar da formação. São disciplinas que estimulam a articulação do núcleo estruturante ao tecnológico e atuam como disciplinas "âncoras" para práticas interdisciplinares;

- Núcleo Tecnológico (NT): relativo a conhecimentos da formação técnica específica, de acordo com o campo de conhecimentos do eixo tecnológico, com a atuação profissional e as regulamentações do exercício da profissão.

- Núcleo de Prática Profissional (NPP): relativo às práticas e recursos que sustentam a construção de propostas de intervenções nas realidades profissionais mais propriamente ditas. (IFMG, 2017, p. 38 e 39)

17 O estudante que opta pela integração do curso técnico profissionalizante também pode cursar, dentro da carga horária prevista, as disciplinas dos Campos de Integração Curricular. 
Com base nestes quatros núcleos, o EMI/IFMG apresenta em sua matriz quais componentes curriculares que fazem parte de cada núcleo. Todos os núcleos são responsáveis por construírem práticas interdisciplinares, com destaque para o Núcleo articulador e o Núcleo de prática profissional.

Para isso, o EMI/IFMG propõe a adoção de um currículo integrado baseando-se nas quatro propostas de integração curricular de Regattieri e Castro (2013), sendo elas: "a integração das disciplinas em quatro áreas de conhecimento; a integração por meio de um núcleo de atividades criativas ou transformadoras; a integração por projetos ou centros de interesse e a integração por eixos temáticos" (IFMG, 2017, p. 40).

Recorremos aos autores Regattieri e Castro (2013) para melhor compreensão das quatro propostas de integração curricular. $\mathrm{Na}$ integração das disciplinas em quatro áreas de conhecimento (Linguagens, Matemática, Ciências Naturais, Ciências Humanas) definem-se objetivos de aprendizagens comuns específicos de cada área, que podem estar relacionados à preparação básica para o trabalho, a outras práticas sociais ou à educação profissional de nível técnico. $\mathrm{Na}$ integração por meio de um núcleo de atividades criativas ou transformadoras, as quatro áreas de conhecimento giram em torno de um Núcleo de Educação para o Trabalho e demais Práticas Sociais ${ }^{18}$, com foco na pesquisa e trabalho. $\mathrm{Na}$ integração por projetos ou centros de interesse, a escola, com base nos interesses dos alunos, nas áreas de conhecimento e no Núcleo de Educação para o Trabalho e demais Práticas Sociais, propõe aos alunos a construção de um projeto de pesquisa e intervenção. Na integração por eixos temáticos, alunos e professores desenvolvem projetos de pesquisa e intervenção a partir de uma dimensão articuladora, sendo elas: trabalho, ciência e cultura e tecnologia.

Assim, o EMI/IFMG propõe que a partir da integração entre os conteúdos sejam desenvolvidos projetos interdisciplinares ao longo do ano através de um currículo integrado.

A proposta curricular do EMII/SEEMG propõe a integração dos componentes da Base Nacional Comum com a parte Flexível do Currículo. Sua matriz curricular é constituída por duas partes: formação básica e formação flexível, com a possibilidade de um curso técnico profissionalizante. A formação básica diz respeito às áreas do conhecimento, indicadas nas Diretrizes Curriculares Nacionais e, agora, pela Base Nacional Comum Curricular do Ensino Médio, com seus respectivos componentes. A formação flexível é composta por três Campos de Integração Curricular (Cultura, Arte e Cidadania; Múltiplas Linguagens, Comunicação e Mídias; Pesquisa e Inovação Tecnológica) ou pela Formação Técnica e Profissional (MINAS GERAIS, 2018).

Inicialmente o Documento Orientador do EMII/SEEMG apresenta a concepção de currículo e, com base em Santomé (1998), apresenta que o currículo integrado "é aquele que pode e deve ser praticado por todos os atores educativos da comunidade escolar, [...] desde que seja amplamente discutido e construído com a participação dos jovens" (MINAS GERAIS, 2018, p.9). Baseando-se em Bernstein (1996), o documento apresenta que o currículo

\footnotetext{
${ }^{18}$ O Núcleo de Educação para o Trabalho e demais Práticas Sociais é "promotor de pesquisas e de atividades relacionadas às quatro dimensões articuladoras do currículo: trabalho, cultura, ciência e tecnologia" (REGATTIERI; CASTRO, 2013, p.277)
} 
integrado possibilita que as disciplinas sejam consideradas em uma perspectiva de relação, promovendo, deste modo, maior participação de professores e estudantes e maior integração dos saberes escolares e saberes dos estudantes.

O EMII/SEEMG apresenta que a adoção de um currículo integrado não se restringe à quantidade de novas disciplinas, mas pressupõe uma nova postura pedagógica capaz de romper com a fragmentação do currículo. O EMII/SEEMG traz, além disso, que todas as escolas que ofertam este projeto de ensino médio devem desenvolver um currículo integrado, interdisciplinar e interdimensional (aquele que possibilita o exercício dos atuais quatro pilares da Educação: o aprender a conhecer, o aprender a ser, o aprender a fazer e o aprender a viver).

$\mathrm{Na}$ organização curricular do EMII/SEEMG, devido à parte flexível do currículo, as aulas referentes aos componentes da Base Nacional Comum e do curso técnico já vêm pré-estabelecidas, entretanto, as aulas dos campos de integração curricular, não obrigatórias ${ }^{19}$, são escolhidas pelos alunos, dentre um leque de opções muito maior daquele ofertado nos núcleos politécnicos, indo ao encontro dos objetivos pessoais e projetos de vida de cada estudante. No EMI/IFMG, por sua vez, todas as aulas dos núcleos politécnicos já vêm préestabelecidas no curso, ofertando, para tanto, a mesma trajetória para todos os estudantes. Compreendemos que cada escola da rede estadual de Minas Gerais que oferte o EMII/SEEMG irá apresentar em seu curso uma matriz curricular diferente, conforme os interesses e singularidades do grupo de estudantes que cada escola atende a cada ano, diferentemente do EMI/IFMG que possui a mesma matriz curricular para todos os seus estudantes.

As duas propostas falam sobre o currículo integrado, sobre a necessidade e importância de se trabalhar interdisciplinarmente os componentes curriculares da formação geral ou básica e formação profissional. Esta compreensão exige que o ensino reducionista, comprometido com o desenvolvimento de algumas atividades humanas em detrimento de outras, seja criticado a fim de superarmos a fragmentação e a hierarquização das disciplinas do currículo.

Segundo Melo e Silva (2017), o conceito de currículo integrado deve ser compreendido no sentido de uma formação integral, no sentido de totalidade ${ }^{20} \mathrm{e}$ não simplesmente como uma junção de disciplinas de formação básica e profissional. Ramos (2017) explica melhor este conceito, abordando que no currículo integrado os conteúdos devem ser aprendidos de acordo com o seu campo científico de origem (disciplinaridade) e relacionados a outras áreas de conhecimento (interdisciplinaridade). Assim, o currículo integrado não anula a organização por disciplinas, mas propõe que os conteúdos sejam trabalhados em articulação com as demais disciplinas, combatendo, assim, a fragmentação do conhecimento (BRAZ, 2014). Neste entendimento, cada disciplina transmite 0 conhecimento respectivo da sua área articuladamente com os demais conteúdos, ou seja, de forma interdisciplinar.

\footnotetext{
${ }^{19}$ As aulas de Pesquisa e Intervenção são obrigatórias paras as duas modalidades do EMII/SEEMG e as aulas de aprofundamento do ENEM são obrigatórias para a modalidade integrada aos Campos de Integração Curricular.

${ }_{20}$ Para Melo e Silva (2017), o sentido de totalidade diz respeito a uma formação completa, relacionando trabalho ciência e cultura.
} 


\section{CONSIDERAÇÕES FINAIS}

Este estudo buscou analisar o Ensino Médio Integrado ao Curso Técnico em Administração ofertado no Instituto Federal de Educação, Ciência e Tecnologia de Ribeiro das Neves e o Ensino Médio Integral e Integrado da Secretaria de Estado de Educação de Minas Gerais.

Verificamos que as duas propostas de ensino médio têm como finalidade a formação humana integral dos estudantes. O EMI/IFMG - Ensino Médio Integrado do IFMG/Campus Ribeirão das Neves - apresentou em sua finalidade uma formação humana integral através da integração entre formação geral e formação técnica profissionalizante articulada ao trabalho, ciência, tecnologia e cultura. Apesar dos Institutos Federais possuírem autonomia administrativa, patrimonial, financeira, didático-pedagógica e disciplinar, conforme a Lei $11.892 / 2008$, acreditamos que todos caminham na direção de se especializarem na oferta de uma educação profissional integrada ao ensino médio, pois é uma de suas finalidades. Já o EMII/SEEMG devido à oferta de duas modalidades; ora integrado à formação técnica profissionalizante, ora integrado a diferentes conteúdos e experiências através dos Campos de Integração Curricular, não evidencia a finalidade de cada modalidade.

Verificamos que as duas propostas atendem a determinação da LBD, no 9394/1996, de ampliação da jornada escolar e que o EMII/SEEMG possui uma carga horária superior de 1400 horas se comparado ao EMI/IFMG, o que poderia equivaler a um ano a mais de estudo. Entretanto, com este estudo não se pode afirmar que aumento desta carga horária é um fator de melhoria ou não na qualidade do ensino e na aprendizagem dos estudantes.

Percebemos que estes dois projetos de ensino médio contribuem para que a Meta 10 do Plano Nacional de Educação, de oferecer no mínimo 25\%(vinte e cinco por cento) das matrículas na forma integrada à educação profissional para os jovens e adultos do ensino fundamental e médio, seja atingida. Entretanto, percebemos que apesar dos avanços, a quantidade de vagas destinadas a esta modalidade ainda é pequena se comparada à demanda existente. Além da pequena quantidade de vagas existentes, o processo seletivo no EMI/IFMG é outro fator dificultador para o estudante filho da classe trabalhadora e público-alvo desta instituição conseguir uma vaga nesta modalidade, pois ou terá que competir com estudantes oriundos da rede privada, ou terá que concorrer por uma vaga entre o quantitativo de 50\% (cinquenta por cento) reservadas para 8 grupos distintos compostos por candidatos que tenham cursado integralmente o ensino fundamental em escolas públicas.

Por fim, verificamos que as duas propostas defendem o currículo integrado, salientando a importância do trabalho interdisciplinar com os componentes curriculares da formação geral ou básica e formação profissional.

Através deste estudo verificamos que o Instituto Federal de Minas Gerais/Campus Ribeirão das Neves faz parte de uma rede federal especializada na oferta da educação profissional e tecnológica, atuando há10 anos na modalidade do Ensino Médio Integrado. O estado de Minas Gerais está dando seus primeiros passos na oferta de um Ensino Médio Integral Integrado, 
apresentando duas modalidades para isso: uma integrada ao curso técnico profissionalizante e outra integrada aos Campos de Integração Curricular. Percebemos que o Ensino Médio Integrado do IFMG/Campus de Ribeirão das Neves propõe a integração da formação geral e formação profissional, ou seja, é uma modalidade integrada a um curso técnico profissionalizante. O Ensino Médio Integral e Integrado de Minas Gerais, por sua vez, propõe a integração dos componentes da Base Nacional Comum (formação básica) com a parte Flexível do Currículo, com a possibilidade de um curso técnico profissionalizante, apresentando, assim, duas modalidades: uma integrada a um curso técnico profissionalizante e outra integrada aos Campos de Integração Curricular. As duas propostas têm aspectos distintos, mas enfatizam uma formação humana integral e a adoção de um currículo integrado.

Essas considerações aqui apresentadas não se encerram com este estudo. Salienta-se a importância da realização de estudos sobre o real funcionamento do Ensino Médio Integrado das duas propostas analisadas, de forma a dar continuidade à pesquisa realizada.

\section{REFERÊNCIAS}

ARAUJO, Ronaldo Marcos de Lima; FRIGOTTO, Gaudêncio. Práticas pedagógicas e ensino integrado. Revista Educação em Questão, Natal, v. 52, n. 38, p. 61-80, maio/ago. 2015.

ARTIAGA, Débora Martins; ALVES, Daniela Alves de. Perspectivas dos alunos sobre o Ensino Médio Integrado: por que o fazem? In: ARAÚJO, Adilson Cesar; SILVA, Claudio Nei Nascimento da. (orgs.). Ensino médio integrado no Brasil: fundamentos, práticas e desafios. Brasília: Ed. IFB, 2017.p. 257 - 279.

BARDIN, Laurence. Análise de Conteúdo. São Paulo: Edições 70, 2002.

BRASIL. Decreto n. 5.154, de 23 de julho de 2004. Regulamenta o $\S 2^{\circ}$ do art. 36 e os arts. 39 a 41 da Lei no 9.394, de 20 de dezembro de 1996, que estabelece as diretrizes e bases da educação nacional, e dá outras providências. Brasília, 2004.

BRASIL. Lei no 9394/96, de 20 de dezembro de 1996. Estabelece as diretrizes e bases da Educação Nacional. Brasília, 1996.

BRASIL. Lei n. 11.892, de 29 de dezembro de 2008. Institui a Rede Federal de Educação Profissional, Científica e Tecnológica, cria os Institutos Federais de Educação, Ciência e Tecnologia, e dá outras providências. Brasília, 2008.

BRASIL. Ministério da Educação. Documento Base: educação profissional técnica de nível médio integrada ao ensino médio. Brasília, 2007. Disponível em: $<$ http://portal.mec.gov.br/setec/arquivos/pdf/documento base.pdf >. Acesso em: 21 jan. 2019.

BRASIL. Ministério da Educação. Formação de professores do ensino médio etapa I - caderno I: ensino médio e formação humana integral. Brasília, 2013.

Disponível em: <http://observatoriodajuventude.ufmg.br/pacto-

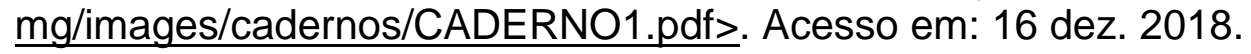


BRAZ, Ana Ângela Araújo. Desafios no Currículo do Ensino Médio Integrado à Educação Profissional na Escola Estadual de Educação Profissional Rodrigues Braz. Dissertação (Mestrado Profissional) - Faculdade de Educação, Universidade Federal de Juiz de Fora, Juiz de Fora, 2014.

CIAVATTA, Maria. A formação integrada: a escola e o trabalho como lugares de memória e identidade. In: FRIGOTTO, G.; CIAVATTA, M.; RAMOS, M.

(org.). Ensino Médio Integrado: concepção e contradições. 2. ed. São Paulo: Cortez, 2010. p. 83-105.

CIAVATTA, Maria; RAMOS, Marise. Ensino Médio Integrado. In: CALDART, R. S.; PEREIRA, I. B.; ALENTEJANO, P.; FRIGOTTO, G. Dicionário da Educação do Campo. São Paulo: Expressão Popular, 2012. p. 307-315.

CRUZ SOBRINHO, Sidinei. Da natureza jurídica Dos IFs e do Ensino Médio Integrado. Ensino em Foco, [S.I.], v. 1, n. 2, p. 34-43, set. 2018. Disponível em: $<$ https://publicacoes.ifba.edu.br/index.php/ensinoemfoco/article/view/446>. Acesso em: 17 mar. 2019.

INSTITUTO FEDERAL DE EDUCAÇÃO, CIÊNCIA E TECNOLOGIA DE MINAS GERAIS CAMPUS RIBEIRÃO DAS NEVES. Projeto Pedagógico do Curso Técnico em Administração Integrado ao Ensino Médio. Ribeirão das Neves, 2017. Disponível em:

$<$ https://www2.ifmg.edu.br/ribeiraodasneves/arquivos/nossos-cursos-arquivos/ppctecnico-em-administracao-integrado-versao-final-18-08-2017.pdf>. Acesso em 16 jan. 2019.

MELO, Mayara Soares de; SILVA, Roberto Ribeiro da. Ensino Médio Integrado à Educação Profissional: os desafios na consolidação de uma educação politécnica. In: ARAÚJO, Adilson Cesar; SILVA, Claudio Nei Nascimento da. (org.). Ensino médio integrado no Brasil: fundamentos, práticas e desafios. Brasília: Ed. IFB, 2017. p. 184-198.

MINAS GERAIS. Documento Orientador da Política de Educação Integral e Integrada e Implementação das Escolas Polo de Educação Múltipla em Minas Gerais. Belo Horizonte, 2017. Disponível em:

$<$ http://www2.educacao.mg.gov.br/images/documentos/Documento\%20Pol\%C3\% ADtica\%20de\%20Educa\%C3\%A7\%C3\%A30\%20Integral\%20e\%20Integrada\%20F INAL.pdf >. Acesso em: 20 mar. 2019.

MINAS GERAIS. Documento Orientador do Projeto Pedagógico para Escolas Polo de Educação Múltipla/ POLEM que ofertam Ensino Médio Integral e Integrado. Belo Horizonte, 2018. Disponível em: <http://www.dcs.ufv.br/wpcontent/uploads/DOCUMENTO-ORIENTADOR-2018-20-dezembro-2017.pdf >. Acesso em: 05 dez. 2018.

MOLL. Jaqueline. Reformar para retardar: a lógica da mudança no EM. Revista Retratos da Escola, Brasília, v. 11, n. 20, p. 61-74, jan./jun. 2017. Disponível em: <http//www.esforce.org.br>. Acesso em: 20 mar. 2019.

REGATTIERI, Marilza Machado Gomes; CASTRO, Jane Margareth. (org).

Currículo integrado para o Ensino Médio: das normas à prática transformadora. Brasília: UNESCO, 2013. 
RAMOS, Marise. Possibilidades e desafios na organização do currículo integrado. In: FRIGOTTO, G.; CIAVATTA, M.; RAMOS, M. (org.). Ensino médio integrado: concepção e contradições. São Paulo: Cortez, 2010. p. 106-125.

RAMOS, Marise. Concepção do Ensino Médio Integrado. [S.I.], 2008. Disponível em: <https://tecnicadmiwj.files.wordpress.com/2008/09/textoconcepcao-do-ensino-medio-integrado-marise-ramos1.pdf $>$. Acesso em: 15 dez. 2018.

RAMOS, Marise. Ensino Médio Integrado: lutas históricas e resistências em tempos de Regressão. In: ARAÚJO, Adilson Cesar; SILVA, Claudio Nei Nascimento da. (org.). Ensino médio integrado no Brasil: fundamentos, práticas e desafios. Brasília: Ed. IFB, 2017. p. 20-43.

SILVA, Katharine Ninive Pinto; RAMOS, Marise. O Ensino Médio Integrado no contexto da Avaliação por resultados. Educ. Soc., Campinas, v. 39, n. 144, p.567583, jul.- set., 2018. 